\author{
Irina Nikolaeva, Elena Kovgan, Natalia KošKareva
}

\title{
Communicative roles in Ostyak syntax
}

\begin{abstract}
In Northern Ostyak the distribution of semantic roles in syntactic positions depends on communicative factors, i.e. on the communicative roles of the sentence elements which denote the participants of the situation. The communicative roles which affect the marking of actants and the type of sentence construction are permanent topic, temporary topic and focus. The paper deals with the rules of selecting the construction of simple and polypredicative sentences according to the combination of semantic and communicative roles.
\end{abstract}

\section{Introduction}

The present paper deals with the interaction of the morphosyntactic and communicative levels of sentence structure in the northern Ostyak dialects. The effect of the communicative factors on Ostyak morphosyntax has been frequently mentioned in connection with the three semantically synonymic constructions - subjective, objective and passive (see e.g. Honti 1984, Szalacsek 1984, Marcantonio 1988, Kulonen 1989: 286-292 and others). As far as the authors know, however, the rules of selecting one of the alternative constructions have not been considered in the context of other phenomena related to them. In our opinion, they are a constituent of the entire mechanism of marking the communicative characteristics of sentence elements which, in many respects, is central to Ostyak syntax.

The main terms used in this paper may be defined as follows. The sentence is considered to be the result of the interaction of three levels 
- semantic, communicative and morphosyntactic. The semantic level contains information about the external situation described in the sentence. Its units are the predicate and the semantic roles denoting the participants in the situation. In this paper the semantic relations A-P-V and A-P-R-V1 are analyzed.

The communicative level "packs" the semantic information into a sentence. We regard the communicative roles as its units - the set of communicative characteristics of the sentence element affecting its surface (including combinatory) properties. ${ }^{2}$ For our purpose it is convenient to single out three opposing communicative roles - topic $1\left(\mathrm{~T}_{1}\right)$, topic $2\left(\mathrm{~T}_{2}\right)$ and focus $(\mathrm{F})$. Roughly speaking, the sentence element not having any of the aforementioned roles is communicatively neutral.

There exist many approaches for determining each communicative role, but we shall not discuss them in detail here. As is well known, the term "topic" has several meanings. First, it may be identified with theme, a traditional notion of the Prague School Functionalism, which, in its turn, is described in two ways - as the given element (Mathesius), or as the sentence element bearing minimum new information (Hornby, Halliday). Secondly, topic (contrastive topic, topic of the "English style") denotes the semantically, syntactically and intonationally marked element $X$ in sentences like "As for ' $X, .$. " or " $X, . . . "$ (Chafe, Haiman). Thirdly, topic (resumptive topic, topic of the "Chinese style") is understood as a constituent having a presupposition of referentiality and determining the framework of the main predication. In so-called "topic-prominent" languages it does not necessarily take the actant position and is directly subordinated to S (Haiman, Li \& Thompson), whereas in languages of the Indo-European type it usually takes the position of the subject. A theory has also been advanced about the complimentary distribution of the topic in the second and third sense in different languages (Parshin 1983: 189).

The term "topic 1", which we use, is closest to the third meaning of the term. The choice of $T_{1}$ is determined by several communicative factors: on the one hand, markedness in the discourse presuming aforementionedness, definiteness and giveness, and on the other hand, the focus of the speaker's interest, i.e. the greatest importance in the situation in question for the speaker. Thus, $\mathrm{T}_{1}$ is set by the context, and it 
is relevant that for any part of the text there may be only one participant denoted as $\mathrm{T}_{1}$. In folklore texts having, as a rule, one main hero, the sentence element that names him has priority in taking the communicative role of $T_{1}$, even if it was mentioned only once at the beginning of the text; then its name is replaced by a zero anaphora, though in intermediate sentences other elements may correspond to the nuclear syntactic positions. We have not considered cases of consituational givenness of $T_{1}$. However, it has been noticed that in a dialogue when the main participant of the situation is one of the communicants, the properties of $T_{1}$ are acquired by the personal pronouns of the 1 st and 2 nd person and in this sense a dialogue may be treated as a sequence of several texts, each of which has its own $\mathrm{T}_{1}$ (on the ambivalent nature of a dialogue see e.g. Sgall \& Gajičova 1975).

The communicative role of $\mathrm{T}_{2}$ is also determined by the discourse and referential status of the sentence element. This term is however more conventional as it does not correspond to the traditional usage and it may be rather related to the traditional concept of "given", i.e. activated in the consciousness of the listener (Chafe 1982). An obligatory property of $T_{2}$ as distinct from $T_{1}$ is its being mentioned in the nearest left context. It is clear that in any part of the text (sometimes within the same sentence) there may be more than one $T_{2}$. Just as in the case of $T_{1}$, referential definiteness is necessary but not sufficient for an element to achieve the status of $T_{2}$, i.e. cases are possible when the referentially definite sentence element is not $T_{2}$ if it is introduced in a context for the first time or not activated in the consciousness of the listener, being a "virtual given" in Baranov's terms (Baranov 1984). The status of $T_{2}$ as distinct from that of $T_{1}$ is obviously kept within a relatively small part of a text. When a sentence element loses its status as $T_{2}$, it may be connected either with its temporary removal from the discourse, or its shift to the position of $T_{1}$, the speaker's focus of interest having changed. Such a change of $T_{1}$ allows the text to be divided into several rather big blocks, each of them having a $\mathrm{T}_{1}$ of its own. In folklore texts it may be depicted by sentences like $\mathrm{O}$ ittam $X$ ewalt mońsem worlijjll, Y pela pittl 'Now my tale is leaving $X$ and coming to $Y$ '.

To sum up: $T_{1}$ is the permanent topic of the text (or of its major portion), named at the beginning and recurrently mentioned; $\mathrm{T}_{2}$ is a 
temporary topic, named in the preceding sentence (or in the preceding part of the same sentence) and mentioned again usually directly thereafter. The differences in the properties of $T_{1}$ and $T_{2}$ are presented in the following table ("+/-" denotes whether a feature is obligatory or not):

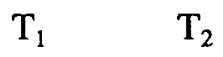

uniqueness

aforementionedness in the

nearest left-hand context

high degree of continuity

The communicative role of focus $(\mathrm{F})$ is connected not with the referential or discourse but with the pragmatic status proper of the sentence element, with explicit or implicit contrast. The focus element is opposed to the other semantically similar elements which constitute a situationally determined set, the focus element taking part in the proposition. In this connection we have considered only the most obvious cases, such as answers to a WH-question or direct contrast expressed in the sentence, though in principle contrast may be understood in a broader sense. Obviously, the ideas "topic" and "focus" are not members of a polar opposition (as, e.g., "theme" and "rheme"); moreover, there exist some similarities between them (see, e.g., Parshin 1983). The communicative role of $F$ has no continuity in the text and is a property of a particular sentence. It is also important to note that unlike the communicative role of topic it may be characteristic not only of the sentence element naming the participants in a situation, but also of the predicate.

The syntactic (morphosyntactic) level of the sentence structure may, generally speaking, be treated in different ways and include different sets of units. We shall now use formal criteria and start from the idea that a definite configuration of semantic and communicative characteristics of sentence elements predetermines some morphosyntactic rules, i.e. the rules of surface coding of a situation. These rules are actually 
the subject of our paper; they include the rules of coreferent deletion, pronominalization and choice of sentence construction. In this context, construction is taken to signify a complex of surface means for binding sentence elements which, in Ostyak, includes morphology (case marking and the form of the predicate) and word order. In simple sentences, constructions with a finite subjective, objective and passive verbal form are possible, and shall be called subjective, objective and passive constructions respectively. The construction of a polypredicative sentence is determined by the structure of the dependent clause (i.e. by the form of the dependent predicate, by the marking and the order of its actants).

As the units of the syntactic level, we shall use the notion of the position of a subject, direct object and indirect object. These terms (subject, in particular) are often defined on the basis of a set of semantic, referential and morphological features (e.g., Keenan). As we view the syntactic level, the contents of these notions is limited by their formal characteristics within the construction - the morphological form and possibilities of agreement peculiar to a particular position. Thus, the sentence element having the morphologically non-marked form of nominative and agreeing in person and number with the verbal form in the construction takes the position of a subject. The direct object is the sentence element which has the form of nominative for nouns and accusative for personal pronouns. In subjective constructions the position of a direct object is also coded by the word order: the subject always precedes the direct object; in objective constructions the same trend is observed, but it is not so strict as the verbal form denotes the number of the direct object. In passive constructions there is no direct object position. The indirect object position is taken by the sentence element marked with an oblique case (the lative $-a /$-ja or instrumental $-n /-a n)$ and does not agree with the verbal form. In the case of dependent clauses, the notions of the position of a dependent subject, dependent direct object and dependent indirect object will be used respectively. It should be borne in mind that the ability of a sentence element to adopt a given syntactic position depends on the definite combination of the semantic and communicative roles.

The material for this paper consists of special phrases, examples and short texts, which the informants were asked to translate; folklore texts 
were also analyzed. Most examples are taken from the Šuryškary dialect (they are not specially marked), but we also have examples from the Kazym dialect (Kaz) and the Sob' form of the Obdorsk dialect $(\mathrm{O})$. The authors express their profound gratitude to the informants, principally Svetlana Val'gamova from Suryškary and Andrej Kaksin from Kazym.

2. The communicative role of topic and the constructions of a simple sentence

Hereinafter the context setting the communicative roles in the sentences analyzed is given in square brackets.

\subsection{Semantic structure A-P}

To express the semantic relations A-P in Ostyak, the subjective, objective and passive constructions are used. In the subjective and objective constructions, A takes the role of subject and $\mathrm{P}$ the role of the direct object. In the passive constructions $P$ is promoted to the position of subject and $\mathrm{A}$ is demoted to an indirect object in the instrumental form. Seven types of distribution of the semantic and communicative roles are possible for the structure in question:

$\mathrm{A}[-\mathrm{T}]-\mathrm{P}[-\mathrm{T}]-\mathrm{V} \rightarrow \mathrm{A}[\mathrm{nom}]-\mathrm{P}[\mathrm{nom}]-\mathrm{V}[\mathrm{sub}]$

[Mŭj mŏlxatl us? What happened yesterday?]

Jŭwan Petra reskas.

John Peter hit-past-3sg.sub

John hit Peter.

(2) $\quad \mathrm{A}\left[\mathrm{T}_{1}\right]-\mathrm{P}[-\mathrm{T}]-\mathrm{V} \rightarrow \mathrm{A}[\mathrm{nom}]-\mathrm{P}[\mathrm{nom}]-\mathrm{V}[\mathrm{sub}]$

[Jŭwan mŭj weras? What did John do?]

Lŭw (Jŭwan) Petra reskas.

he (John) Peter hit-past-3sg.sub

He (John) hit Peter. 
(3) $\quad \mathrm{A}\left[\mathrm{T}_{1}\right]-\mathrm{P}\left[\mathrm{T}_{2}\right]-\mathrm{V} \rightarrow \mathrm{A}[\mathrm{nom}]-\mathrm{P}[\mathrm{n}][\mathrm{nom}] /[\mathrm{pr}][\mathrm{acc}]-\mathrm{V}[\mathrm{ob}]$

[Jŭwan mŭj weras Petraja? What did John do to Peter?]

Lŭw (Jŭwan) tumel (Petra) reskasli.

he (John) this (Peter) hit-past-3sg.ob

He (John) hit him (Peter).

(4)

$\mathrm{A}\left[\mathrm{T}_{2}\right]-\mathrm{P}\left[\mathrm{T}_{1}\right]-\mathrm{V} \rightarrow \mathrm{P}[$ nom $]-\mathrm{A}[$ instr]-V[pas]

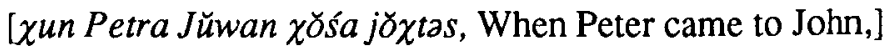

Petra Jüwanan reskasa.

Peter John-instr hit-past-3sg.pas

Peter was hit by John.

(5) $\quad \mathrm{A}\left[\mathrm{T}_{2}\right]-\mathrm{P}[-\mathrm{T}]-\mathrm{V} \rightarrow \mathrm{A}[$ nom $]-\mathrm{P}[$ nom $]-\mathrm{V}[$ sub]

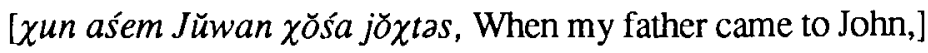

tumel (Jŭwan) Petra reskas.

this (John) Peter hit-past-3sg.sub

he (John) hit Peter.

(6) $\quad \mathrm{A}[-\mathrm{T}]-\mathrm{P}\left[\mathrm{T}_{1}\right]-\mathrm{V} \rightarrow \mathrm{P}[$ nom]-A[instr]-V[pas]

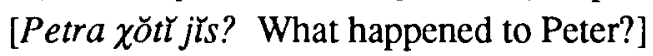

Lŭw (Petra) Jŭwanan reskasa.

he (Peter) John-instr hit-past-3sg.pas

He was hit by John.

(7) $\quad \mathrm{A}[-\mathrm{T}]-\mathrm{P}\left[\mathrm{T}_{2}\right]-\mathrm{V} \rightarrow \mathrm{P}[$ nom $]-\mathrm{A}[$ instr]-V[pas $]$

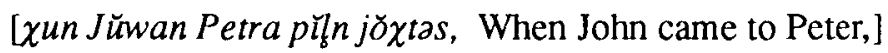

tŭmel (Petra) Mišajan reskasa.

this (Peter) Mike-instr hit-past-3sg.pas

Mike hit him (Peter). ${ }^{3}$

The dependence of the construction and its syntactic positions on the combination of the communicative and semantic roles is shown by the following table ("sub", "ob" and "pas" in this case denote the corresponding construction, the figures showing numbers of examples): 


\begin{tabular}{|c|c|c|c|}
\hline & $\mathrm{T}_{1}$ & $\mathrm{~T}_{2}$ & $-\mathrm{T}$ \\
\hline $\mathrm{T}_{1}$ & $\mathrm{~T}$ & $\mathrm{ob}(3)$ & $\operatorname{sub}(2)$ \\
\hline$-\mathrm{T}$ & $\operatorname{pas}(6)$ & $\operatorname{pas}(7)$ & $\operatorname{sub}(1)$ \\
\hline
\end{tabular}

Thus, the syntactic position of a subject may be taken by actants definitely combining semantic and communicative roles. The frequency of the correspondence of the communicative roles to the position of a subject is reflected by hierarchy (8); ">" means here "is more often the subject":

$$
\mathrm{T}_{1}>\mathrm{T}_{2}>-\mathrm{T}
$$

Starting from hierarchy (8), one can formulate the following conditions of the usage of constructions:

- the condition of the usage of a passive construction is higher level of $P$ as compared to $A$ in hierarchy (8), examples (4), (6), (7);

- the condition of the usage of the subjective and objective constructions is the level of $\mathrm{P}$ not higher than that of A in hierarchy (8), the objective construction marking $\mathrm{T}_{2}$-topicalization of $\mathrm{P}$ (example (3)) and the subjective one marking its absence (examples (1), (2), (5)).

A particular case are personal pronouns which have no instrumental form in the northern Ostyak dialects ${ }^{4}$ and correspondingly cannot act as A in passive constructions. In contexts which demand a passive transformation, if $\mathrm{A}$ has a deictic status of [pr], the objective construction takes place in which $A[\mathrm{pr}]$ is the subject:

(9) [context (4), (6), (7)]

Ma lüwel (Petra) reskasem.

I he-acc (Peter) hit-past-1sg.ob

I hit him (Peter). 
In other words, the deictic status of $\mathrm{A}[\mathrm{pr}]$ a priori determines its highest level in the hierarchy (8). A[pr] has the communicative role of $T_{1}$ independent of its contextual conditions and correspondingly always takes the syntactic position of subject. When introduced into a text, the change of $T_{1}$ takes place automaticaly, the former $T_{1}$ in the role of $P$ takes the communicative role of $\mathrm{T}_{2}$, which determines the choice of the objective construction in example (9).

\subsection{Semantic structure A-P-R}

The semantic relation A-P-R is expressed with two types of subjective, objective and passive constructions. Type I embraces subjective and objective constructions in which $\mathrm{A}$ takes the position of a subject, $\mathrm{P}$ that of direct object and $\mathrm{R}$ that of an indirect object (marked with the lative); as well as their passive transformations in which $\mathrm{P}$ is promoted to subject and $A$ and $R$ are indirect objects, $A$ being marked with the instrumental, $R$ with the lative:

$$
\mathrm{A}[\text { nom]-P[nom]-R[lat]-V } \rightarrow \mathrm{P}[\text { nom]-R[lat]-A[instr]-V[pas] }
$$

Type II includes objective constructions in which A takes the position of subject, $R$ that of direct object, and $P$ that of indirect object in the form of the instrumental; as well as their passive transformations in which $\mathrm{R}$ is the subject, and $\mathrm{A}$ and $\mathrm{P}$ are indirect objects in the instrumental form:

$$
\begin{aligned}
& \mathrm{A}[\text { nom }]-\mathrm{R}[\text { nom }]-\mathrm{P}[\text { instr]-V}[\mathrm{ob}] \rightarrow \mathrm{R}[\text { nom }]-\mathrm{P}[\text { instr]- } \\
& \mathrm{A}[\text { instr]-V[pas] }
\end{aligned}
$$

Subjective constructions of type II (i.e. with $\mathrm{R}$ as direct object) do not exist.

The semantic and communicative roles may be distributed as follows: 
(12) $\quad \mathrm{A}\left[\mathrm{T}_{1}\right]-\mathrm{P}\left[\mathrm{T}_{2}\right]-\mathrm{R}\left[\mathrm{T}_{2}\right]-\mathrm{V} \rightarrow \mathrm{A}[\mathrm{nom}]-\mathrm{R}[$ lat $]-\mathrm{P}[\mathrm{nom}]-\mathrm{V}[\mathrm{ob}]$ [Jüwan Petraja an tus pa John brought a cup to Peter and] (lŭw/Jŭwan) (tŭmela/Petraja) (tăm an) măslt.

he/John this/Peter-lat this cup give-past-3sg.ob He (John) gave it (this cup) to him (Peter).

$\mathrm{A}\left[\mathrm{T}_{1}\right]-\mathrm{P}\left[\mathrm{T}_{2}\right]-\mathrm{R}[-\mathrm{T}]-\mathrm{V} \rightarrow \mathrm{A}[\mathrm{nom}]-\mathrm{R}[\mathrm{lat}]-\mathrm{P}[\mathrm{nom}]-\mathrm{V}[\mathrm{ob}]$ [Jüwan an tus pa John brought a cup and] (lŭw/Jŭwan) Petraja (tăm an) măslŭ. he/John Peter-lat this cup give-past-3sg.ob He (John) gave it (this cup) to Peter.

(14) $\quad \mathrm{A}\left[\mathrm{T}_{1}\right]-\mathrm{P}[-\mathrm{T}]-\mathrm{R}\left[\mathrm{T}_{2}\right]-\mathrm{V} \rightarrow \mathrm{A}[\mathrm{nom}]-\mathrm{R}[$ nom]-P[instr]-V[ob]

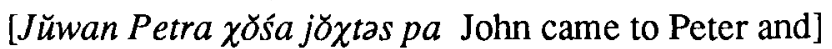
(lüw/Jüwan) (tŭmel) anan măslt.

he/John this cup-instr give-past-3sg.ob gave him (Peter) a cup.

$\mathrm{A}\left[\mathrm{T}_{1}\right]-\mathrm{P}[-\mathrm{T}]-\mathrm{R}[-\mathrm{T}]-\mathrm{V} \rightarrow \mathrm{A}[\mathrm{nom}]-\mathrm{R}[\mathrm{lat}]-\mathrm{P}[$ nom $]-\mathrm{V}[\mathrm{sub}]$ [context (2)] (Lüw/Jŭwan) Petraja an măs. he/John Peter-lat cup give-past-3sg.sub He gave a cup to Peter.

(16) $\quad \mathrm{A}\left[\mathrm{T}_{2}\right]-\mathrm{P}\left[\mathrm{T}_{1}\right]-\mathrm{R}\left[\mathrm{T}_{2}\right]-\mathrm{V} \rightarrow \mathrm{P}[$ nom $]-\mathrm{A}[$ instr]-R[lat]-V[pas] [Tăm an Petrajan Jüwana tusa pa This cup was brought to John by Peter but]

Jŭwanan (tăm an) tŭmela/Petraja jŏðl̆ măsa. John-instr this cup this/Peter-lat back give-past-3sg.pas John gave it back to him (Peter).

(17) $\quad \mathrm{A}\left[\mathrm{T}_{2}\right]-\mathrm{P}\left[\mathrm{T}_{1}\right]-\mathrm{R}[-\mathrm{T}]-\mathrm{V} \rightarrow \mathrm{P}[$ nom]-A[instr]-R[lat]-V[pas] [Tăm an Jüwana tusa pa This cup was brought to John but] (tăm an) Jüwanan Petraja măsa. this cup John-instr Peter-lat give-past-3sg.pas John gave it to Peter. 
$\mathrm{A}[-\mathrm{T}]-\mathrm{P}\left[\mathrm{T}_{1}\right]-\mathrm{R}\left[\mathrm{T}_{2}\right]-\mathrm{V} \rightarrow \mathrm{P}[$ nom $]-\mathrm{A}[$ instr]-R[lat]-V[pas $]$ [context (17)]

(Tăm an) Petrajan lŭwela/Jŭwana ăt măsa.

this cup Peter-instr he/John-lat Neg give-past-3sg.pas

Peter did not give it to him.

(19) $\mathrm{A}[-\mathrm{T}]-\mathrm{P}\left[\mathrm{T}_{1}\right]-\mathrm{R}[-\mathrm{T}]-\mathrm{V} \rightarrow \mathrm{P}[$ nom $]-\mathrm{A}[$ instr]-R[lat $]-\mathrm{V}[\mathrm{pas}]$

[Tămı̆ mŭj an? What kind of cup is this?]

(Tăm an) Jŭwanon Petraja măsa.

this cup John-instr Peter-lat give-past-3sg.pas

It was given to Peter by John.

(20) $\mathrm{A}\left[\mathrm{T}_{2}\right]-\mathrm{P}\left[\mathrm{T}_{2}\right]-\mathrm{R}\left[\mathrm{T}_{1}\right]-\mathrm{V} \rightarrow \mathrm{P}[$ nom]-A[instr]-R[lat]-V[pas]

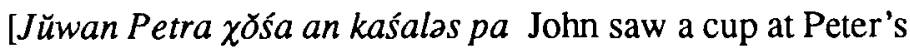
place and]

(tăm an) tŭmeln lŭwela măsa.

this cup this-instr he-lat give-past-3sg.pas

he (Peter) gave it to him (John).

(21) $\mathrm{A}\left[\mathrm{T}_{2}\right]-\mathrm{P}[-\mathrm{T}]-\mathrm{R}\left[\mathrm{T}_{1}\right]-\mathrm{V} \rightarrow \mathrm{R}[$ nom]-A[instr]-P[instr]-V[pas]

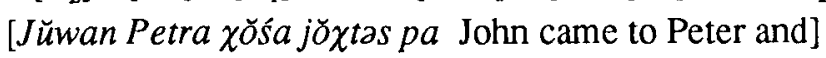

(lŭw/Jŭwan) tŭmelna anan măsa.

he/John this-instr cup-instr give-past-3sg.pas

he (Peter) gave him a cup.

(22) $\mathrm{A}[-\mathrm{T}]-\mathrm{P}\left[\mathrm{T}_{2}\right]-\mathrm{R}\left[\mathrm{T}_{1}\right]-\mathrm{V} \rightarrow \mathrm{P}[$ nom $]-\mathrm{A}[$ instr]-R[lat]-V[pas]

[context (13)]

(Tăm an) Petrajan lŭwela jŏxll ăt măsa.

this cup Peter-instr he-lat back Neg give-past-3sg.pas

Peter did not give it back to him.

$\mathrm{A}[-\mathrm{T}]-\mathrm{P}[-\mathrm{T}]-\mathrm{R}\left[\mathrm{T}_{1}\right]-\mathrm{V} \rightarrow \mathrm{R}[$ nom]-A[instr]-P[instr]-V[pas]

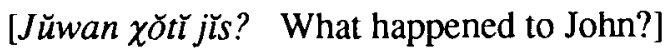

(Lŭw/Jŭwan) Petrajan anan măsa.

he/John Peter-instr cup-instr give-past-3sg.pas

Peter gave a cup to him. 
(24)

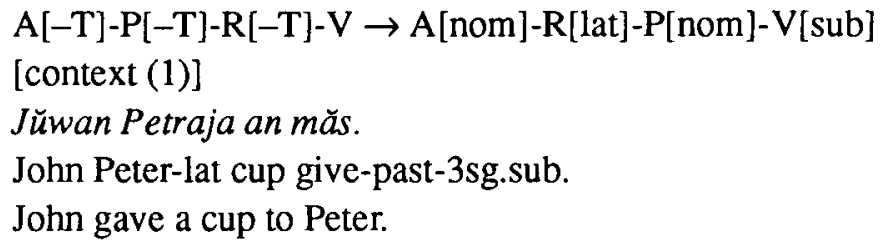

Jŭwan Petraja an măs.

John Peter-lat cup give-past-3sg.sub.

John gave a cup to Peter.

$\mathrm{A}\left[\mathrm{T}_{2}\right]-\mathrm{P}[-\mathrm{T}]-\mathrm{R}[-\mathrm{T}]-\mathrm{V} \rightarrow \mathrm{A}[$ nom $]-\mathrm{R}[$ lat $]-\mathrm{P}[$ nom $]-\mathrm{V}[$ sub]

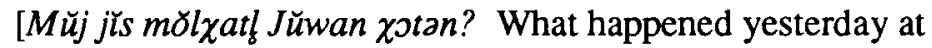
John's house?]

Jŭwan Petraja an măs.

John Peter-lat cup give-past-3sg.sub

John gave a cup to Peter.

$\mathrm{A}[-\mathrm{T}]-\mathrm{P}\left[\mathrm{T}_{2}\right]-\mathrm{R}[-\mathrm{T}]-\mathrm{V} \rightarrow \mathrm{P}[$ nom]-A[instr]-R[lat]-V[pas]

[Mŭj wersan tăm an piln? What did you do with this cup?]

(Tăm an) Jŭwanan Petraja măsa.

this cup John-instr Peter-lat give-past-3sg.pas

It was given to Peter by John.

(27)

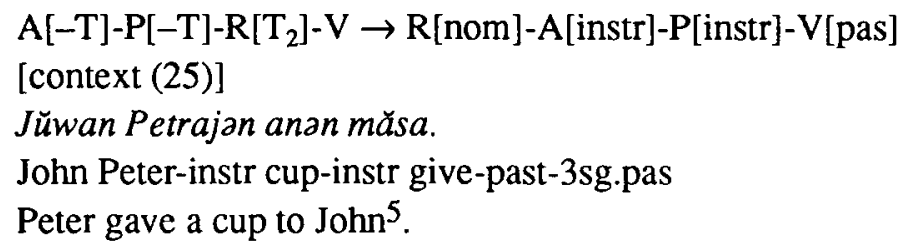

In the cases that require the passive constructions ((16)-(23) and (26)-(27)), the rule described in 2.1. acts: if $A$ is a pronoun, it automatically takes the communicative role of $T_{1}$ (i.e. $A[p r] \rightarrow T_{1}$ ), and in such contexts, the objective construction of type I or II is used:

(28) [context (16)]

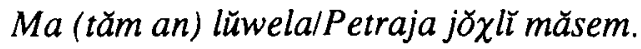

I this cup he/Peter-lat back give-past-1sg.ob.

I gave it back to him. 
(29) [context (17)]

Ma (tăm an) Petraja măsem.

I this cup Peter-lat give-past-1sg.ob

I gave this cup to Peter.

(30) [context (18)]

Ma (tăm an) lŭwela/Jŭwana ăt măsem.

I this cup he/John-lat Neg give-past-1sg.ob

I did not give it to him (John).

(31) [context (19)]

Ma (tăm an) Petraja măsem.

I this cup Peter-lat give-past-1sg.ob.

I gave it to Peter.

(32) [context (20)]

Ma (tăm an) lŭwela jŏxlü măsem.

I this cup he-lat back give-past-1sg.ob

I gave it back to him.

(33) [context (21)]

Ma lüwel anan masem.

I he-acc cup-instr give-past-1sg.ob

I gave a cup to him.

(34) [context (22)]

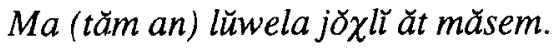

I this cup he-lat back Neg give-past-1sg.ob

I did not give this cup back to him.

(35) [context (23)]

Ma lüwel anan măsem.

I he-acc cup-instr give-past-1sg.ob

I gave a cup to him. 
(36) [context (26)]

Ma (tăm an) Petraja măsem.

I this cup Peter-lat give-past-1sg.ob

I gave it to Peter.

(37) [context (27)]

Ma (lŭwel) anan măsem.

I he-acc cup-instr give-past-1sg.ob

I gave a cup to him.

The influence of the communicative and semantic roles of the sentence elements on the construction type is shown in the following tables:

for $A\left[T_{1}\right]$

\begin{tabular}{|c|c|c|}
\hline & $\mathrm{T}_{2}$ & $-\mathrm{T}$ \\
\hline $\mathrm{T}_{2}$ & obI (12) & obII (14) \\
\hline$-\mathrm{T}$ & obI (13) & subI (15) \\
\hline
\end{tabular}

for $R\left[T_{1}\right]$

\begin{tabular}{|c|c|c|}
\hline & $\mathrm{T}_{2}$ & $-\mathrm{T}$ \\
\hline $\mathrm{T}_{2}$ & pasI (20) & pasI (22) \\
\hline$-T$ & pasII (21) & pasII (23) \\
\hline
\end{tabular}
for $\mathrm{P}\left[\mathrm{T}_{1}\right]$

\begin{tabular}{|c|c|c|}
\hline D & $\mathrm{T}_{2}$ & $-\mathrm{T}$ \\
\hline $\mathrm{T}_{2}$ & pasI (16) & pasI (18) \\
\hline$-\mathrm{T}$ & pasI (17) & pasI (19) \\
\hline
\end{tabular}

for $\mathrm{T}_{2}, \mathrm{~T}_{1}$ lacking

\begin{tabular}{|c|c|c|c|}
\hline $\mathrm{T}_{2}$ & $\mathrm{~A}$ & $\mathrm{P}$ & $\mathrm{R}$ \\
\hline & subI (25) & pasI (26) & pasII (27) \\
\hline
\end{tabular}

Thus, the choice of construction types is determined by the following factors:

- the passive construction is conditioned by a higher level in hierarchy (8) of P (type I) or R (type II) as compared to A. The choice 
between constructions pasI and pasII, i.e. the choice of a subject ( $\mathrm{P}$ or $\mathrm{R}$ ) in this case is determined by the topicalization of $\mathrm{P}: \mathrm{P}$ being topical, it takes the position of a subject (examples (16)-(20), (22), (26), construction pasI); $\mathrm{P}$ being untopical, the position of a subject is taken by $\mathrm{R}$ (examples (21), (23), (27), construction pasII).

- the choice of the subjective or objective construction is conditioned by the level of $\mathrm{P}$ and $\mathrm{R}$ not higher than that of $\mathrm{A}$. In these cases, $P$ and $R$ having different communicative roles $\left(T_{2}\right.$ and $\left.-T\right)$, the position of a direct object is taken by the sentence element with the communicative role of a higher level $\left(\mathrm{T}_{2}\right)$ - either $\mathrm{P}$ (example (13), construction obI), or $\mathrm{R}$ (example (14), construction obII). If $\mathrm{P}$ and $\mathrm{R}$ have the same communicative roles $\left(P\left[T_{2}\right]-R\left[T_{2}\right]\right.$ or $\left.P[-T]-R[-T]\right)$, the position of a direct object is taken by $P$, in the case of a topical $P$ an objective construction is chosen (12), and for untopical $\mathrm{P}$ a subjective one ((15), (25)).

It is clear that in that system there are no subjective constructions of type II as

$$
\begin{aligned}
& \text { *Jŭwan Petra anan măs. } \\
& \text { John Peter cup-instr give-past-3sg.sub } \\
& \text { John gave a cup to Peter, }
\end{aligned}
$$

because the position of a direct object for $\mathrm{R}$ is compatible only with the communicative role of $\mathrm{T}_{2}$, and $\mathrm{T}_{2}$-topicalization of a direct object always requires an objective construction.

The lack, or to be more precise its restricted usage in $\mathrm{O}$, of an instrumental form for the personal pronouns means that it is impossible for $\mathrm{P}[\mathrm{pr}]$ to take the position of an indirect object. For natural and semantic reasons, in structures A-P-R, $\mathrm{P}[\mathrm{pr}]$ is used very seldom and has in such cases the communicative role of $T_{1}$ or $T_{2}$ which brings about the constructions pasI or obI, respectively:

\section{$\mathrm{P}[\mathrm{pr}]\left[\mathrm{T}_{1}\right]$}

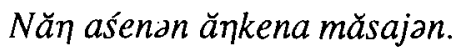

you father-2sg-instr mother-2sg-lat give-past-2sg.pas

Your father gave you to your mother. 
(40) $\mathrm{P}[\mathrm{pr}]\left[\mathrm{T}_{2}\right]$

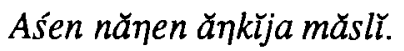

father-2sg you-acc mother-2sg-lat give-past-2sg.ob

Your father gave you to your mother.

Bearing in mind 2.1. and 2.2., we may conclude that this or that syntactic position may be taken by the sentence element in a certain way combining the semantic and the communicative roles. The correspondence of a sentence element to some syntactic position, in its turn, determines the choice of construction type. This dependence may be shown as follows (" $Y>X$ " means here that $X$ may take the corresponding position only in case there is no $\mathrm{Y}$ in the sentence; the vertical arrows point to the corresponding construction type):

(41) the access hierarchy to the position of a subject

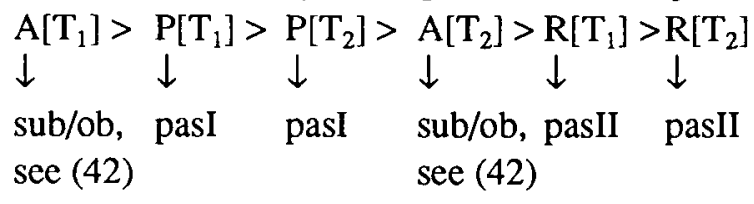

(42) the access hierarchy to the position of direct object in subjective and objective constructions:

$\begin{array}{lll}\mathrm{P}\left[\mathrm{T}_{2}\right]> & \mathrm{R}\left[\mathrm{T}_{2}\right]> & \mathrm{P}[-\mathrm{T}] \\ \downarrow & \downarrow & \downarrow \\ \text { obI } & \text { oblI } & \text { subI }\end{array}$

3. The communicative role of the topic and the constructions of a polypredicative sentence

By polypredicative we mean sentences which include more than one predication and consist of a main clause, which may be an independent simple sentence, and one or two dependent clauses, which cannot form 
an independent sentence. The type of construction of the main clause is selected according to the rules given in 2 . The dependent predication is expressed with a dependent predicate (a participle form) and generally precedes the main one. Any significant element of the main clause may be coreferent with any significant element of the dependent clause. As far as semantics, syntactic role and structure are concerned, the dependent clause may be of three types. First, it may have circumstantial semantics and this kind of sentence will be called circumstantial. In these clauses the dependent participle has case suffixes or postpositions marking its syntactic and semantic bond with the main clause. Second, the dependent clause may have attributive semantics. In this case, the dependent predicate is used in the nominative and placed in front of the determined noun and has no syntactic position corresponding to the role of determined noun in the situation described by the dependent clause. These sentences will be called relative. We shall not deal here with the third type of polypredicative sentences in which the dependent predicate takes the actant position related to the main predicate (modus verb) and is expressed by the form of the nominative; the choice of construction in this case is supposed to follow the same rules as in the circumstantial clauses (see 3.1.).

In the case of circumstantial and relative clauses three dependent clause constructions are possible: a non-marked construction (nm), a $\mathrm{Px}$-construction (Px) and a passive one. In non-marked and Px-constructions, the position of dependent subject is taken by $A^{\prime}$; in Pxconstructions the dependent predicate of circumstantial clauses and the determined noun in relative clauses has Px which marks the person and the number of $\mathrm{A}^{\prime}$. Thus, Px here has a constructive function as distinct from the cases where it has either a possessive meaning proper or a determining one. In non-marked constructions Px referring to $A^{\prime}$ does not exist. Depending on the syntactic position of $P^{\prime}$ and $R^{\prime}$ (direct object or indirect object), non-marked and Px-constructions of types I and II (see 2.2.) are distinguished. In passive constructions the syntactic position of a dependent subject does not coincide with the role of $\mathrm{A}^{\prime}$ and may be taken by $\mathrm{P}^{\prime}$ or $\mathrm{R}^{\prime}$ (correspondingly, there exist passive constructions of types I or II). In those cases $A^{\prime}$ is marked by the instrumental case which is the only formal marker of the construction, as 
the dependent predicate (participle) has no voice forms. There are no Px-markers with a constructive function in passive constructions.

The choice of a construction depends on semantic and syntactic types of the polypredicative sentence as well as on the combination of communicative and semantic roles of the elements in the dependent clause.

\subsection{Circumstantial clauses}

In polypredicative sentences there is the option of choosing the dependent clause construction with a one-placed intransitive dependent predicate, as distinct from simple sentences in which only a subjective construction is possible. The two communicative roles of $A^{\prime}(T$ and $-T$ ) may be opposed when selecting the construction type ( $T$ here combines the communicative roles of $T_{1}$ and $T_{2}$ ). The following cases are possible:

$-A^{\prime}\left[T_{1}\right]-V^{\prime} \rightarrow A^{\prime}[$ nom $]-V^{\prime}[P x]$

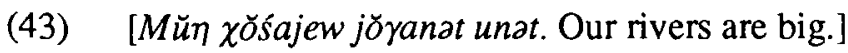

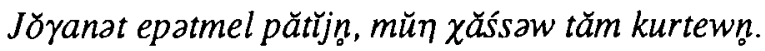
river-pl overflow-part-3pl because ...

The rivers having overflowed, we remained in this village.

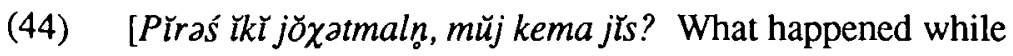
the old man was walking?]

Piraś ı̌k̆ unta joðatmal unť̆, pătlas.

old man forest-lat reach-part-3sg while ...

When the old man reached the forest, it had grown dark.

(45) [Mašinajew atmaś rupǔtas. Our car was out of order.]

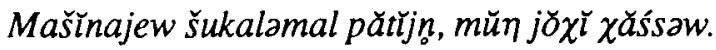

car-1pl break-part-3sg because ...

Our car being broken, we were late. 
(46) [Kŭrem kăšana jı̆s. My foot is aching.]

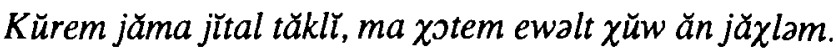

foot-1sg good-lat become-part-3sg until ...

Until my foot gets better, I shall not go far from my house.

$-A^{\prime}\left[T_{2}\right]-V^{\prime} \rightarrow A^{\prime}[$ nom $]-V^{\prime}[P x]$

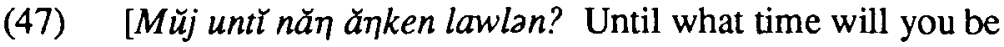
waiting for your mother?]

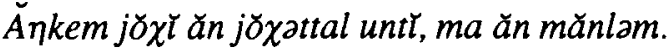
mother-1sg back Neg come-part-3sg until ... I shall not go, until my mother returns home.

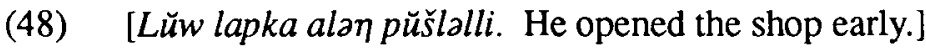

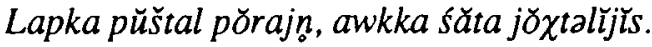

shop open-part-3sg when ...

When the shop was opened, a tame reindeer came there.

Thus, the topicalization of $\mathrm{A}^{\prime}$ is marked by a Px-construction. If $\mathrm{A}^{\prime}$ has deictic pronominal status, its topicalization (in the sense of $T_{1}$ ) is given a priori (see 2.1.); in this case, only a Px-construction is allowed:

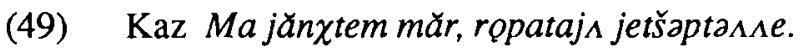
I walk-part-1sg while ...

While I am walking, he will have finished his work.

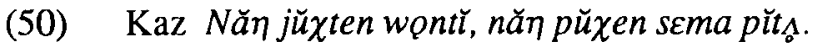
you return-part-2sg until ...

Before you return, a son will be bom to you.

A' being non-topical, a non-marked construction is used:

$-\mathrm{A}^{\prime}[-\mathrm{T}]-\mathrm{V}^{\prime} \rightarrow \mathrm{A}^{\prime}[\mathrm{nm}]-\mathrm{V}^{\prime}$

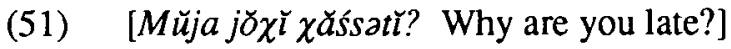

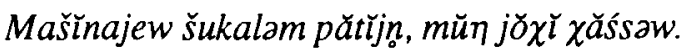
car-1 pl break-part because...

We are late, because our car is out of order [cf. (45)]. 


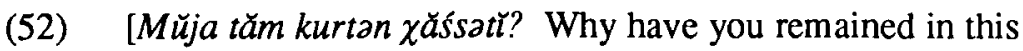
village?]

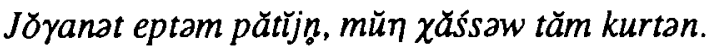

river-pl overflow-part because...

We have remained in this village, because the rivers have overflown [cf. (43)].

(53) [xun pătlas? When had it grown dark?]

Plraś ǐk̆ unta joztam unť, pătlas.

old man forest-lat come-part when ...

It had grown dark, when the old man reached the forest [cf. 44].

(54) [Mŭj unť̆ jolan omastૉ pltlan? Until when will you be at home?]

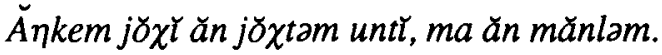
mother-1sg back Neg return-part until ... I shall not go until my mother returns home [cf. (47)].

(55) [zun awkka joxtalljiss? When did the tame reindeer come?] Lapka pŭštt̆ porajn, awkka śăta joxtalĭjts. shop open-part when ...

The tame reindeer came, when the shop was open [cf. (48)].

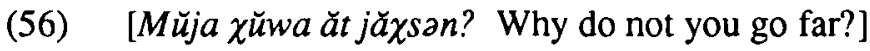

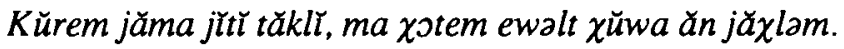
foot-1sg good-lat become-part until ...

Until my foot gets better, I shall not go far from my house [cf. (46)].

In the structures $A^{\prime}-P^{\prime}$ the same seven communicative types are possible as in the simple sentence (see 2.1.). Reliable material is available only for the following cases:
$\mathrm{A}^{\prime}[-\mathrm{T}]-\mathrm{P}^{\prime}\left[\mathrm{T}_{1}\right]-\mathrm{V}^{\prime} \rightarrow \mathrm{P}^{\prime}[$ nom $]-\mathrm{A}^{\prime}[\mathrm{instr}]-\mathrm{V}^{\prime}$
[Lŭw kăšana jŭs. He has fallen ill.]

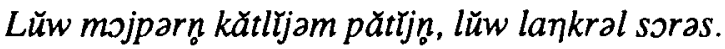
he bear-instr hold-part because ...
He being held by a bear, his shoulder dried in. 
$\mathrm{A}^{\prime}\left[\mathrm{T}_{1}\right]-\mathrm{P}^{\prime}[-\mathrm{T}]-\mathrm{V}^{\prime} \rightarrow \mathrm{A}^{\prime}[\mathrm{nom}]-\mathrm{P}^{\prime}[\mathrm{nom}]-\mathrm{V}^{\prime}[\mathrm{Px}]$

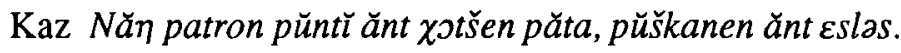

you cartridge charge-Inf Neg can-part because ...

Your gun did not fire, because you cannot charge the cartridges.

In the following group of examples, the context setting the communicative role of $\mathrm{P}^{\prime}\left(-\mathrm{T}\right.$ or $\left.\mathrm{T}_{2}\right)$ is not known:

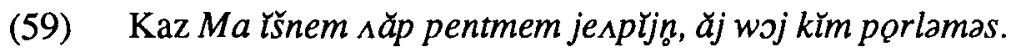

I window down close-part before...

Before I closed the window, the bird had flown away.

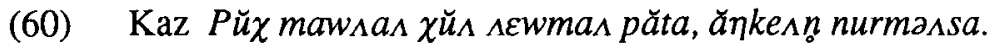
boy sweet-3pl all eat-part-3sg because...

The boy was punished by the mother for having eaten all his sweets.

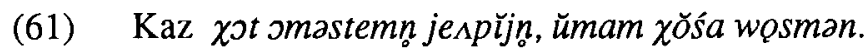
house built-part-1du before...

Before we built the/a house we lived at my sister's.

Taking into account the lack of material we may make up the table:

\begin{tabular}{|c|c|c|c|}
\hline $\mathrm{A}$ & $\mathrm{T}_{1}$ & $\mathrm{~T}_{2}$ & $-\mathrm{T}$ \\
\hline $\mathrm{T}_{1}$ & $\mathrm{P}$ & $?$ & $\mathrm{pas}$ \\
\hline $\mathrm{T}_{2}$ & $\mathrm{Px}$ & & $?$ \\
\hline$-\mathrm{T}$ & $\mathrm{Px}$ & $\mathrm{Px}$ & $\mathrm{nm}$ \\
\hline
\end{tabular}

Apparently similar rules are also valid for structures $A^{\prime}-P^{\prime}-R^{\prime}$ (i.e. the passive construction is supposed to mark the $T_{1}$-topicalization of $\mathrm{P}^{\prime}$ or 
$R^{\prime}$, the choice between the constructions pasI and pasII being determined by hierarchy (41)). We do not, however, have enough material for drawing definite conclusions.

On the basis of the data of polypredicative sentences, the topicalizing role of the right context (i.e. of the main clause) may be shown, which in simple sentences is less obvious. The element of the main and dependent clauses being coreferent (coreference is here denoted by "="), a certain interdependence between their constructions is observed. If $A^{\prime}$ is coreferent with $A$, it automatically takes the status of $T_{1}$, because it is set in a relatively big and completed passage and correspondingly falls within the speaker's focus of interest. The topicalizing context in this case is the polypredicative sentence itself within which the Agent functions. Accordingly, in the dependent clause a Pxconstruction is used, whereas in the main one a subjective or objective construction. When this dependence is broken, $\mathrm{A}^{\prime}$ and $\mathrm{A}$ cannot be coreferent, cf.:

(62) $\quad \mathrm{A}^{\prime}=\mathrm{A}$

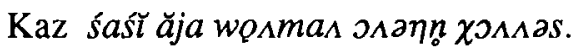
grandmother young-lat be-part-3sg about...

Grandmother is crying for her being young,

(63) $\quad \mathrm{A}^{\prime} \neq \mathrm{A}$

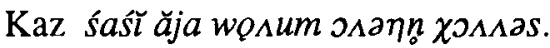

grandmother young-lat be-part about ...

$\mathrm{He}$ is crying for grandmother being young;

(64) $\quad \mathrm{A}^{\prime}=\mathrm{A}$

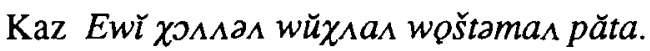

... money-3pl lose-part-3sg because

The girl is crying for her having lost her money,

(65) $\quad \mathrm{A}^{\prime} \neq \mathrm{A}$

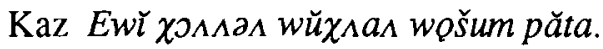

... money-3pl lose-part because

The girl is crying for her money being lost; 
(66) $\quad \mathrm{A}^{\prime}=\mathrm{A}$

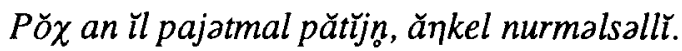
boy cup down drop-part-3sg because...

Because the boy had dropped the cup, he punished his mother,

(67) $\quad \mathrm{A}^{\prime} \neq \mathrm{A}$

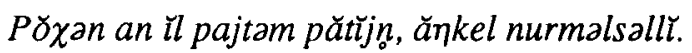
boy-instr cup down drop-part because ...

Because the boy had dropped the cup, he (someone) punished his mother.

The Agent common to the main and dependent clause is, as a rule, presented on the surface not more than once and in the left dislocation (i.e. within the dependent clause), more seldom, at the beginning of the main clause:

O Kürmaś đl măntalna mărĭjŭl. brick down go-part-3sg-loc ... A brick, when it falls, makes noise.

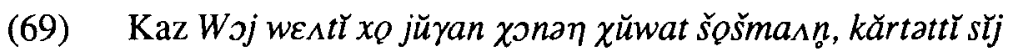

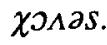

animal kill-part man river bank along walk-part-3sg-loc ... When the hunter was walking along the bank of the river, he heard a cracking noise.

Similarly, if $\mathrm{A}^{\prime}$ is coreferent with $\mathrm{P}$ or $\mathrm{R}$, it has in any case the status of topic independent of the preceding context. In the dependent clause a Px-construction is used, and in the main one, a passive construction , the choice of the subject in which is determined by hierarchy (41):

(70) $\quad \mathrm{A}^{\prime}=\mathrm{P}$

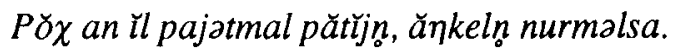

boy cup down drop-part-3sg because...

The boy was punished by his mother for having dropped the cup. 
(71)

$\mathrm{A}^{\prime}=\mathrm{R}$

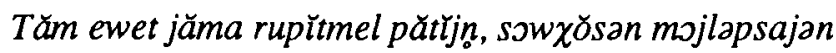
măsajat.

this girl-pl good-lat work-part-3pl because ...

The state farm gave a present to these girls for good work.

If one of the conditions mentioned above is broken, i.e., if there is no Px-construction in the dependent clause as in

(72) Poð an Il pajtam pătĭjn, ănkelñ nurmalsa.

boy cup down drop-part because ...

Because the boy had dropped the cup, he (someone) was punished by his mother,

or, if there is no passive construction in the main clause as in (66), $\mathrm{A}^{\prime}$ and $\mathrm{P}^{\prime}\left(\mathrm{R}^{\prime}\right)$ cannot be coreferent.

In principle, other cases of coreference of elements in the main and dependent clauses are also possible $\left(\mathrm{P}^{\prime}=\mathrm{A}, \mathrm{R}^{\prime}=\mathrm{A}\right.$ etc.); we have discussed only the most typical examples, in the other cases similar rules apparently apply.

\subsection{Relative clauses}

In so far as their structure is concerned, relative clauses are comparable to simple attributive NPs in possessive and non-possessive semantics. In Ostyak, the attribute precedes the determined noun. When the attribute is not possessive, there are no morphological markers of the attributive bond, in other words a non-marked construction is used: kew $\chi v t$ 'stone house', ăj $\chi v t$ 'small house'. Two types of constructions correspond to possessive attributes - a non-marked construction (Jüwan

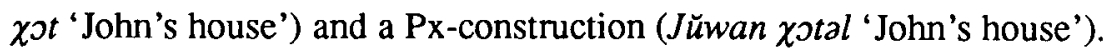
In Px-constructions the determined noun has Px referring to the possessor. If the possessor is a pronoun, only a Px-construction is 
possible (lüw $\chi 0 t a l$ 'his house'); if the possessor is a noun, both constructions are used, though the non-marked is more frequent. For the noun-possessor the Px-construction is used if the possessor has the communicative role of $\mathrm{T}_{1}$, cf::

(73) [xठ̆j semat likkna etsat? Whose eyes became angry?]

Mojpar semat likna etsat.

bear eye-pl ...

The bear's eyes became angry.

(74) [Mojpar omsas. Ma wan jütem săðat, The bear was sitting. When I approached,] mojpar semlal lǐkna etsat.

bear eye-3pl ...

the bear's eyes became angry.

It is peculiar that the Px-construction is often left-dislocated in the sentence, i.e. it is a so-called "topic-prominent" construction. Its constituents may be discontinuous: there may be an adverbial modifier between them, which is impossible in the case of the non-marked construction, cf.:

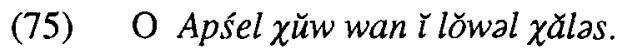
younger brother long short one horse-3sg ...

Sooner or later, one of the younger brother's horses died.

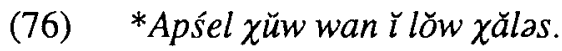

younger brother long short one horse...

Such sentences are often translated by informants with the help of the Russian preposition "u" (cf. for (75): "Долго ли коротко, у младшего брата умерла одна лошадь" - "The younger brother, sooner or later, one of his horses died'), the communicative function of which is known to consist of the pragmatic disjunction of an utterance and topicpromotion (see Krejdlin 1979: 10). In Px-constructions, when the possessor is a noun, the determined noun as distinct from other cases 
automatically receives the status of $T_{2} 6$; therefore, if it is $P$, the subjective construction is not allowed (see 2.1.):

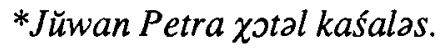

John Peter house-3sg see-past-3sg.sub

John saw Peter's house,

but only

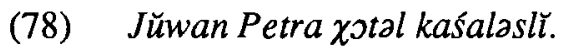
John Peter house-3sg see-past-3sg.ob

or

(79) Petra Øotal Jüwanan kaśalasa.

Peter house-3sg John-instr see-past-3sg.pas.

Relative clauses are in principle similarly organized. The attributive dependent clause is placed before the determined noun which may have a Px-marker. There are no restrictions of relativization, i.e. any element of a deep sentence may be relativized. As the function of relative clauses in the text is the identification of a sentence element having the feature [-given], its semantics mainly determines the non-topical communicative role of a determined noun (cf. Schachter 1973).

Most relative clauses may be divided into two main types depending on the semantic role of the determined noun. If the determined noun has a role of $\mathrm{A}^{\prime}$ (i.e. it is $\mathrm{A}^{\prime}[-\mathrm{T}]$ ), as in simple non-possessive NPs, the non-marked construction is used, in which case the determined noun has no constructively relevant Px referring to $A^{\prime} .^{7}$ This rule works for all structures:

$$
\mathrm{A}^{\prime}-\mathrm{V}^{\prime} \rightarrow \mathrm{V}^{\prime}-\mathrm{A}^{\prime}
$$

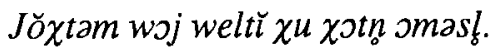

come-part animal kill-part man ...

The hunter who has come is in the house. 
$\mathrm{A}^{\prime}-\mathrm{P}^{\prime}-\mathrm{V} \rightarrow \mathrm{P}^{\prime}[\mathrm{nom}]-\mathrm{V}^{\prime}-\mathrm{A}^{\prime}$

Wŭll welam mojpar ǐkljno kaśalasa.

reindeer kill-part bear ...

The old man noticed the bear that had killed a reindeer.

$\mathrm{A}^{\prime}-\mathrm{P}^{\prime}-\mathrm{R}^{\prime}-\mathrm{V}^{\prime} \rightarrow \mathrm{R}^{\prime}[$ lat $]-\mathrm{P}^{\prime}[\mathrm{nom}]-\mathrm{V}^{\prime}-\mathrm{A}^{\prime}$

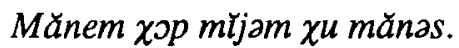

I-lat boat give-part man ...

The man who had given me the boat went away.

In structures $A^{\prime}-P^{\prime}-R^{\prime}$, the position of direct object is taken either by $\mathrm{P}^{\prime}$ or $\mathrm{R}^{\prime}$, i.e. constructions of type I or II are possible conditioned by

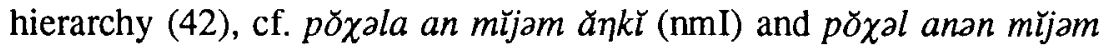

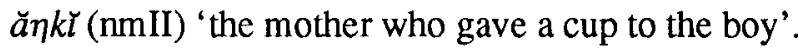

If the determined noun is not $A^{\prime}$ ', there is a position for $A^{\prime}$ in the dependent clause, the $A^{\prime}$ having some communicative role. If $A^{\prime}$ has the communicative role of $\mathrm{T}_{1}$, a Px-construction is used. In these kinds of sentences, the topical element can be $A^{\prime}$ with the deictic status of pronoun:

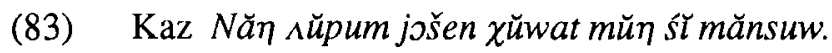
you say-part road-2sg...

We took the road that you had advised.

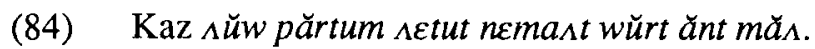

he order-part food-3sg ...

The food that he ordered gives no satisfaction.

Personal pronouns as Agent are often omitted (see 4.1.), therefore, we view the Px-constructions with a zero $\mathrm{A}^{\prime}$ as a variety of this type:

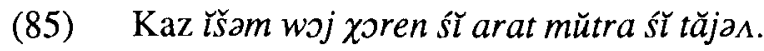

draw-part animal picture-2sg ...

The picture of a bear that you have drawn has so much wisdom. 
The second case of a topical $\left(T_{1}\right) A^{\prime}$ is a sentence in which $A^{\prime}$ is coreferent with A (cf. 3.1.):

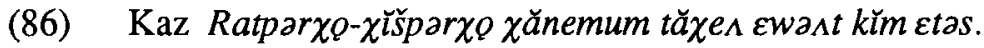

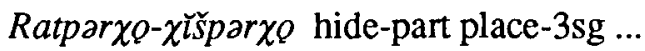

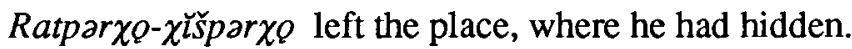

(87) Kaz ı̌mı̆ mońśt mó móśos wana wersase.

woman tell-part tale-3sg ...

The woman shortened the tale she was telling.

With $A^{\prime}\left[-T_{1}\right]$ in structures $A^{\prime}-V^{\prime}$, the non-marked construction is used, whereas in structures $A^{\prime}-P^{\prime}$ and $A^{\prime}-P^{\prime}-R^{\prime}$ the non-marked or passive construction, which have the lack of a constructively relevant Px in common, is selected. The communicative conditions for an opposition between the non-marked and passive constructions for $\mathrm{A}^{\prime}\left[-\mathrm{T}_{1}\right]$ have not been found, at least in our material. We may assume that the passive construction has to do with the topicalization of the determined noun, cf:

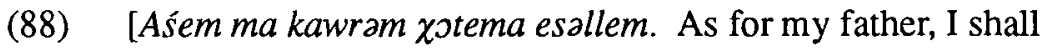
let him into my warm house.]

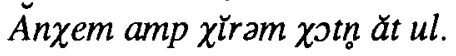
step-mother dog dig-part house-loc ... Let the step-mother live in a house dug by a dog.

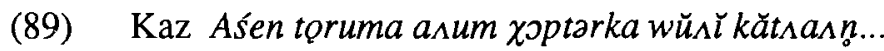
father-2du God-lat promise-part white reindeer... Catch the white reindeer which was promised by your father to God.

On the other hand:

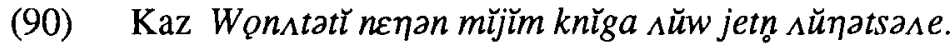
teach-part woman-instr give-part book ... In the evening he read the book given by the teacher. 
(91) Saša aśeln weram nŭmalñ unta jă $\chi \partial s$.

Sasha father-3sg.-instr make-part ski-instr...

Sasha went to the forest on skis made by his father.

In the case of questions for structures $\mathrm{A}^{\prime}-\mathrm{P}^{\prime}-\mathrm{R}^{\prime}$ there is no opposition in constructions of types I and II. The point is that the syntactic function of the determined noun in the dependent clause is not morphologically explicit; therefore, to express the semantics of the construction, the second dependent actant ( $\mathrm{P}^{\prime}$ or $\mathrm{R}^{\prime}$ ) must be morphologically marked.

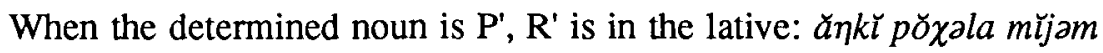

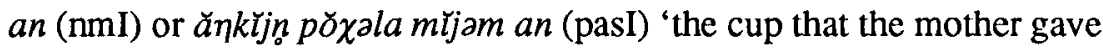
to the boy'; the determined noun being $\mathrm{R}^{\prime}, \mathrm{P}^{\prime}$ has the form of the instrum-

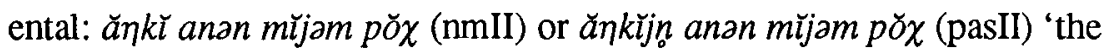
boy to whom the mother gave a cup'. So, in this instance the choice of the construction type (I or II) is influenced by the semantic role of the determined noun and not the communicative characteristics.

\section{The lexical coding of the topical element}

\subsection{Pronominalization and coreferent deletion}

It is well known (see, e.g., Kuno 1982) that more recoverable information can be deleted more easily than unrecoverable. According to this principle, the sentence elements having the communicative roles of $T_{1}$ and $T_{2}$ in an Ostyak text may undergo coreferent deletion or be replaced by anaphoric elements. There are two groups of rules of coreferent deletion and pronominalization working in the case of a constant (unreplaced) $\mathrm{T}_{1}$, on the one hand, and a replaced $\mathrm{T}_{1}$, on the other.

With a constant $T_{1}$ of the 3rd person, the sentence element which corresponds to this role may be replaced either by the forms of the personal pronouns (lŭw (nom), lŭwel (acc), lŭwela (lat)), or be deleted in the nuclear semantic roles (A, P, R), which is possible because it is this element that is most often coreferent with the actants of other 
sentences in the text; correspondingly, it is capable of controlling the coreferent bonds within the sentence as well. Reference is maintained by personal verbal formants, whereas in polypredicative sentences Pxmarkers are used with the dependent predicate or the determined noun (see 3.). These agreement morphemes can refer only to $T_{1}$ :

(92) Jŭwan Petra pŭln pŏtartas. Petra mănas. Yj ı̌l̆ omsas. Tăm iǩjon kaśalasa.

John talked to Peter. Peter went. An old man was sitting. The old man saw him (Peter).

Thus, the personal pronouns in the role of A are practically always deleted (as a rule, they are present on the surface level only if they have the communicative role of $F$ (see 5.) or are a replaced topic, see below).

With a constant $T_{1}$, the $T_{2}$ can also be deleted in the role of $P$ or $R$. Then reference is regularly rendered with the help of the objective marker of a verb (see examples above). In the case of the constant $T_{1}$ of the 3rd person, $P\left[T_{2}\right]$ and $R\left[T_{2}\right]$ are almost never expressed by the forms of personal pronouns of the 3rd person lüwel and lüwela, because in this case (at least with a definite semantics of the predicate) they may be understood only as reflexive ones, see 4.2 . In principle, the objective verbal marker is here sufficient to maintain reference; in colloquial speech other means may be used when necessary: replacing $\mathrm{T}_{2}$ by the

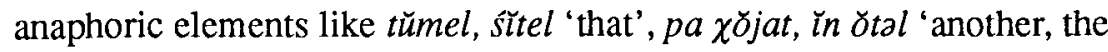
latter' or by simply repeating the noun in the text:

(93) [Jŭwan Petra pŭln přtartas pa John talked to Peter and]

(tŭmel) reskaslĭ.

(that) hit-past-3sg.ob

John talked to Peter and hit him.

(94) [context (93)]

Petra anan măsl̆.

Peter cup-instr give-past-3sg.ob

gave a cup to him,

etc. 
If a constant $T_{1}$ is one of the communicants, i.e. is expressed by personal pronoun of the 1st or 2nd person, the anaphoric substitution of form of a 3rd person pronoun for $\mathrm{P}\left[\mathrm{T}_{2}\right]$ and $\mathrm{R}\left[\mathrm{T}_{2}\right]$ is allowed, because it does not bring about a referential conflict:

(95) [Ma Petra pŭln pŏtartasam pa I talked to Peter and] lüwel reskasem.

he-acc hit-past-1sg.ob

hit him.

(96) [context (95)]

lŭwel anan măsem.

he-acc cup-instr give-past-1sg.ob

gave a cup to him.

The deletion of $T_{2}$ in the role of $A$ is less regular, because $A\left[T_{2}\right][$ instr] is not marked in the verbal form, but probable:

(97) [context (93)]

reskasa.

hit-past-3sg.pas

he (Peter) hit him (John).

The substitution of $T_{1}$ may occur in two ways. First, it automatically takes place when introducing $\mathrm{A}[\mathrm{pr}]$ into the text (see 2.1.). In this case, the former $T_{1}$ in the role of $P$ or $R$ receives the status of $T_{2}$, and is demoted to the position of direct object and replaced by forms of the $3 \mathrm{rd}$ person pronouns understood as referring only to the former $\mathrm{T}_{1}$ :

(98) [Jŭwan Petra reskaslı̆. John hit Peter].

Sišan ma lŭwel woštasem.

Therefore I he-acc drive out-past-1sg.ob

Therefore, I drove him (John) out.

The former $T_{2}$ here retains its communicative status and may be substituted by an anaphoric element or named once more: 
(99) [context (98)]

Sišon ma tŭmel/Petra woštasem.

therefore I that/Peter drive out-past-1sg.ob

Therefore, I drove him (Peter) out.

Secondly, the new $\mathrm{T}_{1}$ may correspond to the noun which moved from the position of $T_{2}$ or $-T$, therefore, the noun to receive the status of $\mathrm{T}_{1}$ (unlike the personal pronouns) must participate in at least two predications.

On the whole, the problem of the choice of $T_{1}$ requires a special investigation into the organization of discourse, which we have not discussed in particular. Some formal criteria were formulated for polypredicative sentences only (see 3.): obligatory status of $T_{1}$ is typical of $\mathrm{A}^{\prime}$ coreferent with one of the nuclear syntactic elements of the main clause, because the corresponding sentence element is set by two contact predications. For the dependent clause, therefore, the topicalizing role is fulfilled by the right context. Actually, it is probable that analogous rules may take effect in sequences of simple sentences as well.

\subsection{Reflexivization}

In Ostyak there are no reflexive pronouns, their function in case roles and in the role of a possessive attribute being performed by the corresponding personal pronouns. The controller of reflexivization is the sentence element which takes the syntactic position of a subject independent of its semantic role (A, P or R), cf.:
(100) Aśeln pðð reskasa.
father-3sg-instr son hit-past-3sg.pas
The father hit his son,

while

(101) *Poxl aśĭjn reskasa.

son-3sg father-instr hit-past-3sg.pas 
and

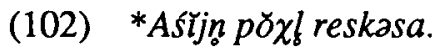

father-instr son-3sg hit-past-3sg.pas

are both impossible. The sentence element with a reflexive component in its grammatical meaning (i.e. personal pronoun coreferent with the subject or NP in which the possessor is coreferent with the subject) will be called a reflexive element. Thus, the reflexive element cannot take the position of subject, but any semantic role may correspond to it in other syntactic positions. The reflexive component of the semantics of a sentence element unambiguously stipulates its topical $\left(T_{1}\right.$ or $\left.T_{2}\right)$ role and thus not only its semantic role but also the sentence construction. Consequently, the communicative role of the reflexive elements is not determined contextually, but is rather inherent. Here we can more precisely formulate the rules for selecting the constructions in the simple sentence described in 2.

In structures A-P, if $\mathrm{P}$ is a reflexive element, it takes the position of the direct object and has the communicative role of $T_{2}$. The objective construction is observed here even in those sentences, when the context could cause the subjective one:

(103) [context (1), (2)]

Jŭwan lüwel reskasl̆.

John he-acc hit-past-3sg.ob

John hit himself.

(104) [context (1), (2)]

Jŭwan (lüw) wŭlel reskaslĭ.

John (he) reindeer-3sg hit-past-3sg.ob

John hit his (John's) reindeer.

It is clear that in these contexts the formant of the objective conjugation may be the only surface marker of the reflexivity of $\mathrm{P}, \mathrm{cf}$. 
(105) [context (1), (2)]

Jŭwan wŭlel reskas.

John reindeer-3sg hit-past-3sg.sub

John hit his (someone's) reindeer.

In structures A-P-R, the reflexive $\mathrm{R}$ also has the communicative role of $T_{2}$, in this instance the objective construction of type $I$ is used if $P$ is topicalized:

(106) [context (19)]

Jüwan (tăm an) lŭw aśela măsl̆.

John (this cup) he father-3sg-lat give-past-3sg.ob

John gave this cup to his father,

and the objective construction of type II is used when P is not the topic:

(107) [context (15)]

Jŭwan lŭw aśel anan măsl̆.

John he father-3sg cup-instr give-past-3sg.ob

John gave his father a cup.

If $\mathrm{P}$ and $\mathrm{R}$ both are reflexive, the choice of the construction type depends on hierarchy (42), i.e. the position of direct object is taken by $P$.

Thus, the following rules of reflexivization are observed in simple sentences: a) the reflexive element cannot take the position of subject but is controlled by the subject; b) it may have the semantic role of $A$ only in case $A$ is not the subject, i.e. is not $T_{1} ; c$ ) in the role of $P$ or $R$, the reflexive element is $T_{2}$, the $A$ controlling it being $T_{1}$.

We have not investigated the rules of reflexivization in polypredicative sentences. 
5. The communicative role of focus and the construction of the simple sentence

As mentioned in 1, a predicate, as well as the sentence element denoting the participants of a situation, may have the communicative role of $F$. The former case is, however, the least trivial: in particular, it is not quite clear if the predicate is focused in the answer to a question like "What did X do?" (our material shows that it is not, although, on the other hand, any other sentence element in the answer to a question can be focused). Moreover, there obviously exist more subtle mechanisms connected with the organization of a discourse and setting the communicative role of $\mathrm{F}$ for the predicate (the contrast in circumstants or non-nuclear actants, the enumeration of predicates etc.). Dependencies of this kind have not been considered; however, they must be borne in mind when interpreting texts.

We have only considered the following cases of the effect of the communicative role of $\mathrm{F}$ on the construction of a simple sentence.

$-A[F]-P(-R)-V \rightarrow P[$ nom $](-R[$ lat $])-A[$ instr]-V[pas $]$

(108) Wŭl̆ Jŭwanan welsa, ănta Petrajn. reindeer John-instr kill-past-3sg.pas ... John killed the reindeer, not Peter.

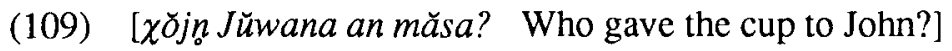
An Jŭwana Petrajn măsa. cup John-lat Peter-instr give-past-3sg.pas Peter did.

$-\mathrm{A}[\mathrm{pr}][\mathrm{F}]-\mathrm{P}(-\mathrm{R})-\mathrm{V} \rightarrow \mathrm{P}[\mathrm{nom}](-\mathrm{R}[\mathrm{lat}])-\mathrm{A}[\mathrm{pr}][\mathrm{nom}]-\mathrm{V}[\mathrm{ob}]$

(110) Wŭlı̆ ma welsem, ănta Petra. reindeer I kill-past-1sg.ob ... I killed the reindeer, not Peter. 
(111) [context (109)]

An Jŭwana ma măsem.

cup John-lat I give-past-1sg.ob

I did.

$-A-P[F](-R)-V \rightarrow A[$ nom $]-(R[$ lat $]-) P[n][$ nom $] /[p r][a c c]-V[s u b]$

(112) Jŭwan wŭll̆ welas, ănta mojpar. John reindeer kill-past-3sg.sub ... John killed a reindeer, not a bear.

(113) [Aśel mŭj măs Jŭwana? What did the father give to John?] Aśel Jŭwana keši măs, ănta lajam.

father John-lat knife give-past-3sg.sub ...

Father gave John a knife, not an axe.

$-A-P-R[F]-V \rightarrow A[n o m]-P[n o m]-R[1 a t]-V[o b]$

(114) Aśel an Jŭwana măslĭ, ănta Petraja. father-3sg cup John-lat give-past-3sg.ob ... His father gave a/the cup to John, not to Peter.

$-A-P(-R)-V[F] \rightarrow A[n o m](-R[l a t])-P[n o m]-V[o b]$

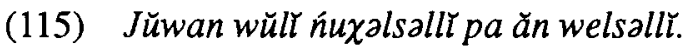
John reindeer reach-past-3sg.ob ... John reached a/the reindeer but did not kill it.

(116) Aśel Jüwana an tusl̆ pa ăn măsl̆. father-3sg John-lat cup bring-past-3sg.ob ... His father brought a/the cup to John, but did not give it to him.

The choice between the subjective and objective construction does not depend on deictic factors (determined vs. undetermined P). In fact, the subjective construction is also used when $P[F]$ is referentially determined, including the case of $\mathrm{P}[\mathrm{pr}]$ or reflexive $\mathrm{P}$ : 
(117) Jŭwan năฤen wantas, ănta manem.

John you-acc see-past-3sg.sub ...

John saw you, not me.

(118) Jŭwan lŭw anal tus, ănta manem.

John he cup-3sg bring-past-3sg.sub ...

John brought his cup, not mine.

On the other hand, in case of $V[F]$ the objective construction is used, even if $P$ is indefinite:

(119) Jŭwan amuj wŭll ńuxalsallı pa ăn welsall̆. John some reindeer reach-past-3sg.ob ... John reached a reindeer, but did not kill it.

A special role in marking focus contexts belongs to the so-called rhematic (in our terms, focus) items, which are certain logical particles and quantifiers having a contrastive component in their semantic interpretation. The semantics of such lexemes in the Ob-Ugrian languages has not been studied, therefore, our observations are of a very preliminary nature. It is important that the introduction of a focus item into a sentence definitely determines the communicative role of $F$ for the sentence element as its scope and, correspondingly, the construction type. The list of focus items given below may perhaps be more precisely specified and enlarged. It is worth noting that the role of the focus items (at least some of them) is less expressed for A, in the sense that some informants produce various constructions in this case (at present we cannot say whether this is caused by the destructive influence of Russian syntax or by deeper mechanisms). For V $[F], P[F]$ and $\mathrm{R}[\mathrm{V}]$ the variation in construction types is not permitted.

For sentence elements denoting the participants in a situation $(A, P$, R) the focus items are:

particle tup 'only'

particles š́, pa, ǔšl 'also, too'

particle $\chi \delta$ lna (pa) 'even'

particle $\chi$ ŏlna 'also' ("noch") 
particle pa 'another, other'

particle $s \tilde{l}$ ' it is... that'

particle $s a ̆ \chi$ 'at all'

particle tup tup 'hardly'

negative pronouns nemalti 'no, nothing', nemaltĭ $\chi ð$ jat 'no one'

interrogative pronouns $\chi \check{\delta j}$ 'who', mŭj 'what', mătl 'which', mŭj $\chi \supset r p \check{l}$ 'what kind of'

Some examples:

$-\mathrm{A}[\mathrm{F}]$

(120) Wŭl̆ tup Jŭwanan welsa.

reindeer only John-instr kill-past-3sg.pas

Only John killed a reindeer.

(121) Wŭlĭ nemalť̆ xojatan ăn welsa.

reindeer no one-instr Neg kill-past-3sg.pas

Nobody killed a reindeer.

$-\mathrm{P}[\mathrm{F}]$

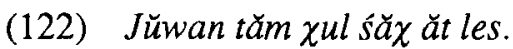

John this fish at all Neg eat-past-3sg.sub

John did not eat this fish at all.

(123) Jŭwan tămı̆ š̃ wantas.

John this precisely see-past-3sg.sub

It was this one that John saw.

$-\mathrm{R}[\mathrm{F}]$

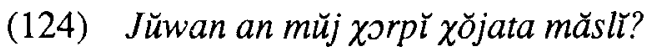

John cup what kind of man-lat give-past-3sg.ob

What kind of man did John give a cup to? 


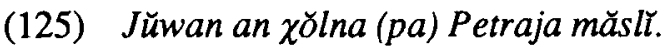

John cup even Peter-lat give-past-3sg.ob

John gave a cup even to Peter.

Focus items determining the communicative role of $\mathrm{V}[\mathrm{F}]$ are:

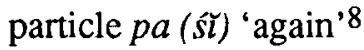

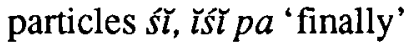

particle tup tup 'just'

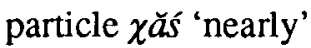

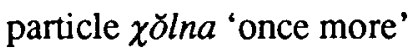

pronoun nemaltĭ 'at all'

pronouns $\chi \varnothing$ lljje, $\chi \varnothing \check{l} l$ 'everything, all'

Some examples:

(126) Jŭwan wŭl̆̌ pa welsallĭ.

John reindeer again kill-past-3sg.ob

John killed a reindeer again.

(127) Jŭwan nemalť ăn welsallt.

John at all Neg kill-past-3sg.ob

John killed nothing at all.

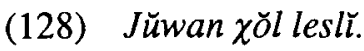

John everything eat-past-3sg.ob

John ate everything.

It is also supposed that the focusing role for the predicate (at least in some cases) may belong to verbal prefixes which are sometimes replaced by focus items. This problem, however, requires special investigation. 


\section{Conclusion}

So, what we claim is:

a) Northem Ostyak is a typical "reference-dominated" language , in terms of Van Valin and Foley (Van Valin, Foley 1982). In languges of this kind, as is well known, the principal means of maintaining reference in a text is a system of "switching" the syntactic functions of the sentence element which is coreferent with the elements of other sentences. Thus, the distribution of semantic roles in syntactic positions is ambiguous: it occurs depending on communicative (mainly, contextually conditioned) factors.

b) A definite configuration of communicative characteristics (statuses) of a sentence element is described using the notion of communicative role. It is not the communicative roles proper that are marked in a sentence, but rather their combination in this or that semantic structure. The type of syntactic construction (including case marking, word order and the form of the predicate) is the means of marking the combination of the communicative and semantic roles.

c) Certain types of constructions (sub vs. ob, Px vs. $\mathrm{nm}$ ) are formally opposed by only one formant: Px-marker or the marker of the objective conjugation (which is known to be historically related to $\mathrm{Px}$ ); so, these formants are the only means to code the combination of semantic and communicative roles. Consequently, such a coding is one of the functions of Px (beside the possessive and determining ones), as well as the sole function of the objective conjugation, which is only secondarily connected with the referential definiteness of direct object. The other morphological markers within the constructions link the function of coding the combination of communicative and semantic roles with marking the syntactic bond of sentence elements.

d) There exist two strategies for coding the combination of communicative roles for two main types of predicate: finite verbs, on the one hand, and infinite verbal forms, on the other. In constructions with a finite verb, it is possible to oppose three communicative roles of topical type $\left(\mathrm{T}_{1}, \mathrm{~T}_{2}\right.$ and $-\mathrm{T}$ ) in structures A-P and A-P-R (in structures with a one-placed intransitive verb, it is unnecessary to express the 
combination of the communicative roles, therefore, there is no alternative choice in the construction). In structures with an infinite verbal form, the topicalization/non-topicalization of Agent is definitely marked, the structure and semantics of relative clauses restricting the possibilities of marking the other communicative roles. ${ }^{9}$

e) Beside these constructions, an additional means of marking the topic may be pronominalization (i.e. the substitution of an anaphoric element for the topical one) and coreferent deletion. The latter forms so-called "topical chains" in which the sentence element having the presupposition of referentiality $\left(\mathrm{T}_{1}\right)$ may be mentioned only once.

f) Generally, the communicative roles are set by the context. In particular cases the communicative role of topic may be set by:

- the deictic status of the personal pronoun in the role of $A\left(T_{1}\right)$;

- the right context in a polypredicative sentence where the dependent $A^{\prime}$ is coreferent with the elements of the main clause $\left(T_{1}\right)$;

- the reflexive status of a sentence element ( $T_{2}$ in the role of $P$ or $R$ ), as well as the coreferent or possessive connection with the reflexive element ( $T_{1}$ in the role of $\left.A\right)$.

g) In focus sentences, i.e. in those sentences in which one of their elements has the communicative role of focus, the neutralization of other communicative roles $\left(\mathrm{T}_{1}, \mathrm{~T}_{2}\right.$ and $\left.-\mathrm{T}\right)$ occures; in the sense that the topicalization of focus element is not marked. This, however, does not bring to the loss of the topic status (at least $T_{1}$ ) by the sentence element in the following text. So, focus sentences fall out of the topical chain, but do not disturb it.

\section{Notes}

1 Abbreviations: A - Agent, P - Patient, R - Recipient (receiver of a concrete donation), $\mathrm{V}$ - predicate, Vsub - verb in the subjective finite form, Vob - verb in the objective finite form, Vpas - verb in the passive finite form, part - participle, nom - nominative, acc - accusative, lat lative, instr - instrumental, loc - locative, $\mathbf{n}$ - noun, $\mathrm{pr}$ - personal pronoun; the elements of a dependent predication are denoted by corresponding symbols with diacritics: $A^{\prime}, P^{\prime}, R^{\prime}, V^{\prime}$; it is not presupposed that constructions must be derived transformationally. 
2 For further details on the concept of the communicative role see e.g. Maslova 1989.

3 The case $A\left[T_{2}\right]-P\left[T_{2}\right]$ is evidently extremely rare.

4 The instrumental forms of personal pronouns have been attested in $\mathrm{O}$, but their usage is restricted only to some special cases.

5 In our material, examples in which two sentence elements have the communicative role of $T_{2}$ and the third one that of $-T$ are lacking.

6 Similar rules work for a reflexive element, see 4.2.

7 It is clear that the determined noun may in principle have a Px, but in this case it marks the possessive relations without the dependent clause.

8 When meaning 'again', participle $p a$ is stressed in a sentence, but when it signifies 'also' it is an enclitic. Similarly, the stressed šl means 'finally', the unstressed one 'also'.

9 The same principle is supposed to work in one more class of infinite predicates that we have not taken into consideration, i.e. in constructions with the forms of the resultative (statal passive).

References

Baranov 1984 = Баранов, А. Н.: Коммуникативно-смысловая оппосиция "данное-новое" (метаязык и некоторые приложения). Москва.

Chafe 1982 = Чейф, У. Л.: Данность, контрастивность, определенность, подлежащие, топики и точка зрения. - Новое в зарубежной лингвистике 11:277-316. Москва.

Honti, L. 1984: K проблеме возникновения объектного спряжения угорских языков. - NyK 86: 341-346.

Krejdlin 1979 = Крейдлин, Г. Е.: Служебные слова в русском языке (семантические и синтаксические аспекты изучения). Москва.

Kulonen, U.-M. 1989: The passive in Ob-Ugrian. MSFOu 203. Helsinki.

Kuno, S. 1982: Principles of discourse deletion - case studies from English, Russian and Japanese. - Journal of Semantics 1: 81-93.

Marcantonio, A. 1989: On the case of the object in Finnish: A typological, diachronic and comparative analysis. - FUF XLVIII (1989), fasc.2-3: $129-170$.

Maslova 1989 = Маслова, Е. С.: Соотношение коммуникативной и синтаксической структур в простом предложении юкагирского языка. Ленинград.

Parshin 1983 = Паршин, П. Б.: Тема и топик: к соотношению понятий. Вопросы восточного языкознания: 186-211. Москва. 
Schachter, P. 1973: Focus and Relativization. - Language 49: 19-46.

Sgall \& Gajiðova 1975 = Сгалл, П. \& Гайова, Е.: Некоторые вопросы смыслово и структуры текста. - Проблемы создания и развития международной системы научной и технической информации, 2: $21-25$.

Szalacsek, M. 1984: The problem of the usage of the definite and indefinite conjugational forms in the northern Ostyak language. - NyK 21: 426-430

Van Valin \& Foley 1982 = Ван Валин, Р. \& Фоли, У.: Референциальноролевая грамматика. - Новое в зарубежной лингвистике 11: 376-410. Москва. 